\title{
Crosstalk effects caused by the geometry of piezoelectric elements in matrix ultrasonic transducers
}

\author{
Israel Sánchez Domínguez*, Pedro Acevedo Contla, Eduardo Moreno Hernández, \\ Marco Antônio von Krüger
}

\begin{abstract}
Crosstalk is a result of the deficiency in the electrical or mechanical isolation between elements. It is a function of the proximity between piezoelectric elements of the transducer or between connections. It can be caused by a series of factors, such as: the deficiency in the electromagnetic shield, the capacitive effect between the elements or the electrical connections, or by the transmission of vibration modes to adjacent elements due to insufficient mechanical isolation. It also depends on the geometry of the elements and the connecting material between elements. The evaluation of the crosstalk effects caused by the geometry of the piezoelectric elements in matrix ultrasonic transducers is presented. Measurement methods of the radiation patterns and vectorial impedance for the identification of crosstalk are described. The procedure of the measurement of crosstalk, done by Sánchez Domínguez and von Krüger (2002), was applied to an eight elements phase onedimension matrix transducer for Doppler ultrasound application. In fact, two cases are presented, in one of them a piezoelectric element of the matrix with initial dimensions of $10.0 \times 4.4 \times 0.66 \mathrm{~mm}$ was used, and in the other case a piezoelectric element with initial dimensions of $10.0 \times 0.7 \times 0.66 \mathrm{~mm}$ was used (element are made of Lead Zirconate Titanate, also called PZT). From the results we deduce that it is possible to reduce the crosstalk effect using insulating material with low electromechanical coupling coefficient between the ceramics of the array or using materials that promote good mechanical insulation between the ceramics.
\end{abstract}

Keywords Crosstalk, Piezoelectric elements, Matrix ultrasonic transducers.

\section{Efeitos de crosstalk causados pela geometria de elementos piezoelétricos na matriz de transdutores ultrassônicos}

Resumo Crosstalk é uma consequência da deficiência no isolamento elétrico ou mecânico entre os elementos; é função da proximidade entre os elementos piezoelétricos do transdutor ou entre as conexões dos mesmos. Pode ser causado por uma série de fatores, tais como: a deficiência da blindagem eletromagnética, o efeito capacitivo entre os elementos ou as conexões elétricas, assim como pela transmissão nos modos de vibração dos elementos adjacentes devido ao seu isolamento mecânico insuficiente. Depende também das dimensões fisicas dos elementos e do material de conexão entre eles. A avaliação dos efeitos do crosstalk causados pela geometria dos elementos piezoelétricos na matriz de transdutores de ultrassom é apresentada. Os métodos de medição dos padrões de radiação e impedância vetorial para a identificação do crosstalk são descritos. O procedimento de medição do crosstalk proposto por Sánchez Domínguez e von Krüger (2002) foi aplicado a um arranjo de oito elementos de uma matriz de transdutores para a aplicação de ultrassom Doppler. De fato, dois estudos de caso são apresentados: no primeiro foi usado um elemento piezoelétrico com dimensões de 10,0 × 4,4 × 0,66 mm, e no segundo, em outro arranjo, utilizou-se um elemento piezoelétrico com dimensões de 10,0 × 0,7 × 0,66 mm (cada elemento da matriz é confeccionado em titanato zirconato de chumbo, também chamado PZT). A partir dos resultados podemos deduzir que é possível reduzir o efeito do crosstalk entre as cerâmicas utilizando um material de isolamento com um coeficiente de acoplamento eletromecânico baixo na matriz, ou empregando materiais que promovam bom isolamento mecânico entre as cerâmicas.

Palavras-chave Crosstalk, Elementos piezoelétricos, Matriz de transdutores ultrassônicos. 


\section{Introduction}

Ultrasound in modern medicine has reached a considerable technological advance; ultrasonic transducers are a good example of this advance. Transducers constructed using a single sensor or an array of sensors are commonly used to focalize and direct the ultrasonic beam (Turnbull and Foster, 1992). The performance of matrix transducers, particularly the phase array is affected by crosstalk, deteriorating the directivity of the ultrasonic beam, among other things (Sánchez Domínguez and von Krüger, 2002). Crosstalk can be either of electrical or mechanical nature. The study of the effect caused by the geometry of the piezoelectric elements in the generation of crosstalk is the main motivation of the present work, the reduction of crosstalk decreases considerably the noise and improves the performance of the ultrasonic matrix transducers. As an introduction, some basic concepts about crosstalk are presented. Materials and methods that were used during the development of the present article are described, as well as the results that validate our conclusions (Smith et al., 1979).

\section{Matrix ultrasonic transducers}

At present, ultrasonic transducers are widely used in the industrial, naval and medical fields with a frequency range from $25 \mathrm{kHz}$ (in cleaning equipment) to $20 \mathrm{MHz}$ in some medical applications (either with a single ceramic, two ceramics in form of $\mathrm{D}$, or in linear and matrix arrays). With the development of electronics and computer science, matrix transducers became very important (Whittingham, 1997). Transducers constructed using piezoelectric elements may work at different frequencies and according to their shape can be of one dimension (1D), two dimensions (2D) and/or annular, as shown in Figure 1 (Shung and Zipparo, 1996).

Matrix transducers from the operational point of view can be linear or phased matrix; these type of transducers are more versatile than transducers of a single element. One of their advantages is the control of focusing and the direction of the beam (Turnbull and Foster, 1992). However, they are more difficult to construct, and demand a complex electronic operation, having a higher cost.

\section{Crosstalk in matrix arrays}

Crosstalk is a result of the deficiency in the electrical or mechanical isolation between elements. It is a function of the proximity between piezoelectric elements of the transducer or between connections. It can be caused by a series of factors, such as: the deficiency in the electromagnetic shield, the capacitive effect between the elements or the electrical connections, or by the transmission of vibration modes to adjacent elements due to insufficient mechanical isolation (Friedrich et al., 1990; Guess and Campbell, 1995; Kino and Desilets, 1979; Smith et al., 1979; Turnbull and Foster, 1992; Wojcik et al., 1996). Crosstalk also depends on the physical dimensions of the elements and the connecting material between them (Gori et al., 2001).

This is an interesting phenomenon in phased matrix whose characteristic is the proximity between the elements. The performance of the transducers is affected by crosstalk; it consists basically on the excitation of an element by adjacent elements reducing the capacity to control the beam direction in transmission and reception (Jaffe et al., 1971). Figure 2 shows a diagram of the mechanical and electrical crosstalk.

Crosstalk as previously mentioned is due to several factors, however, quantitative measurement methods of the level of crosstalk in matrix transducers have not been well-developed yet. Qualitative evaluations presented so far have aimed to improve the images acquired through matrix adjustments by means of algorithms or new systems of image reconstruction. The present work does not implement a new methodology of construction. The main objective is to present a

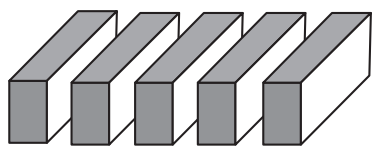

unidimensional

Types of matrix

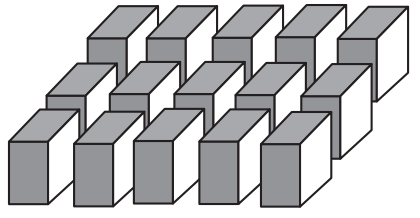

bidimensional

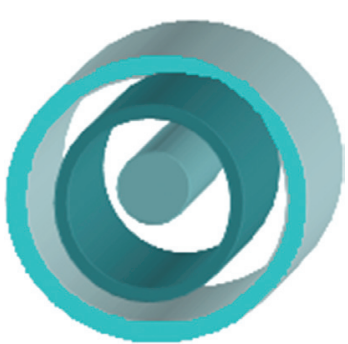

annular

Figure 1. Types of matrix array transducers. 


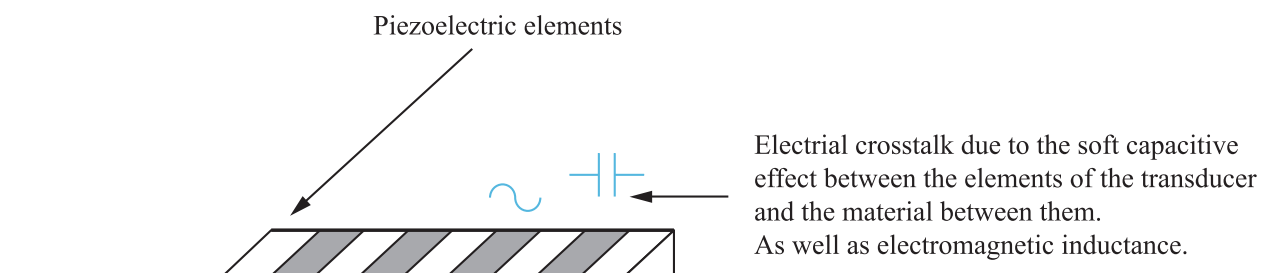

(b)

Mechanical crosstalk is due to the different modes of vibration of the piezoelectric elements.

Insulating material

(a)

Figure 2. Different matching modes between the elements of a matrix that contribute to the generation of crosstalk.

procedure to determine the amount of crosstalk, and to emphasize the dependence between the geometry of the piezoelectric elements and this amount of crosstalk.

The geometry of the piezoelectric elements determines the vibration mode. This is particularly important when the height and the width of the elements are of the same order since a connection between lateral and frontal vibration modes is caused. Figure 2 shows the different forms of interaction between the elements of an array that contribute to the crosstalk phenomenon.

Figure 3 shows a simulation of the effect of crosstalk on the ultrasonic beam using the HP VEE program (Sánchez Domínguez, 2003). Diagrams a) and b) in Figure 3 represent the acoustic main lobes, generated by a two elements matrix array of equal dimensions, excited by a sinusoidal signal of similar amplitude but transmitted at different phases causing the same directivity, but with reduction in the amplitude due to crosstalk.

\section{Material and Methods}

\section{Measurement of the mechanical crosstalk}

Aiming to observe and evaluate mechanical crosstalk, a measurement of the electrical and mechanical connection between elements of two different arrays was made. One of the arrays was made using a ceramic plate (divided into 8 elements) and the other array was made using 8 polished ceramic bars (Figure 4).

Each array consisted of 8 elements with $0.3 \mathrm{~mm}$ width and separated by a $0.05 \mathrm{~mm}$ gap filled with silicon rubber. Due to the distance and the material between elements the response from each element of

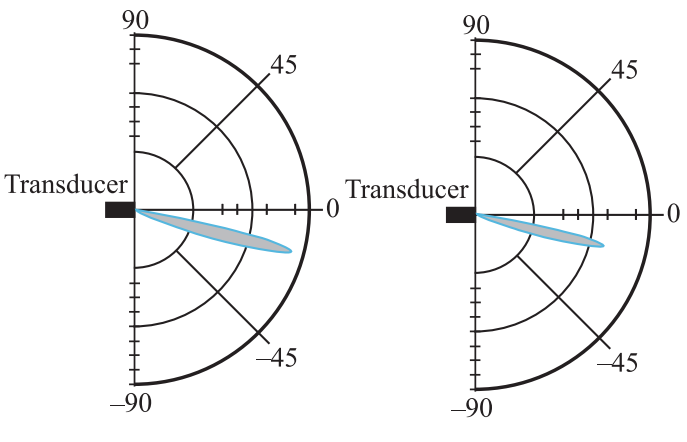

(a) Crosstalk absent

(b) Crosstalk present

Figure 3. Crosstalk effect in an ultrasonic beam generated by a directed phase matrix (simulation using the HP VEE program).

the array was different (Sánchez Domínguez, 2003; Whittingham, 1997). Piezoelectric ceramics of $3.5 \mathrm{MHz}$ (Ferroperm PZ-27) were used in this experiment.

The elements of the matrix were made of Lead Zirconate Titanate (PZT). One element of the array was excited and measurements were made on the remaining elements. The experimental setup consisted of a pulse generator (Avtech Monocycle Generator, model AVB2-TB-PS) to excite the element and a digital oscilloscope (Tektronix, model TDS420) to register the signal captured in each one of the remaining elements as shown in Figure 5. A self-made software was used for displaying the response signals of the elements.

\section{Phase impedance}

The measurement of the impedance vector of an element depending on its size is intended to detect the different vibration modes of the ceramic element based on its geometry. The whole experiment 
Piezoelectric elements

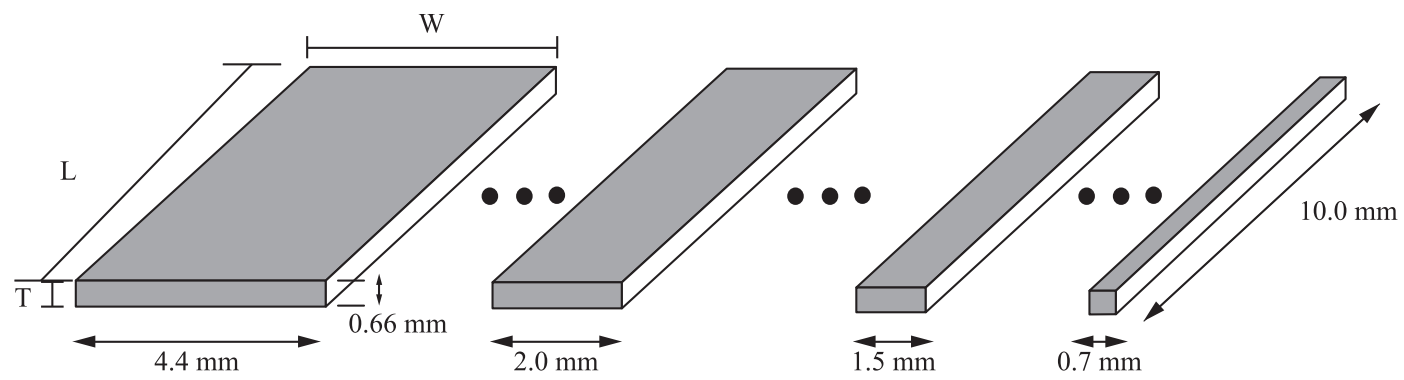

Figure 4. Piezoelectric ceramics with different dimensions (length $\times$ width $\times$ thickness).

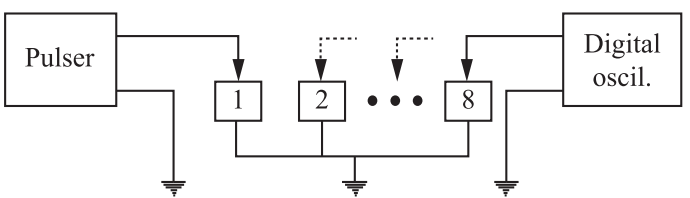

Figure 5. Diagram of the assembly used in the measurement of the attenuation and the wave propagation speed, where one element is excited in the array and measurements are made in the remaining array elements.

was divided into two different cases: an element of $10.0 \times 4.4 \times 0.66 \mathrm{~mm}$ (length $\times$ width $\times$ thickness, measured with a micrometer) was polished until reach $10.0 \times 0.70 \times 0.66 \mathrm{~mm}$ (Figure 4). During the polishing process, measurements of the acoustic field amplitude were made. In the second case the acoustic field amplitude of the $10.0 \times 0.70 \times 0.66 \mathrm{~mm}$ bar was measured. In both cases the ceramic elements were fixed and the hydrophone (Precision Acoustics, needle hydrophone PVDF $0.5 \mathrm{~mm} / 9 \mathrm{~mm}$ ) was free to move.

\section{Radiation patterns}

For a better understanding of the radiation pattern analysis two different cases are presented.

Case 1 - In order to study the radiation pattern of the ceramic element, its geometry was modified, originally being a plate and finally a bar. The ceramic element originally had the following physical dimensions: $10.0 \times 4.4 \times 0.66 \mathrm{~mm}$, then only the width was gradually reduced $(3.8,3.5,3.29,3.15,2.8,2.5,2.0,1.5,1.0,0.75)$ to $10.0 \times 0.7 \times 0.66 \mathrm{~mm}$.

To measure the acoustic field amplitude from each ceramic element of different width in the $x$-axis the following procedure was performed: the hydrophone was positioned at a distance of $8.5 \mathrm{~mm}$ from the ceramic element in the $y$-axis. This position was selected as the central position (point 0 (zero)). The hydrophone was then moved to position $-50.0 \mathrm{~mm}$ in the $x$-axis. From this position a sweep was made in steps of $10.0 \mathrm{~mm}$ in the positive direction of the axis up to the $+50.0 \mathrm{~mm}$ position (Figure 6a). This sweep was made to obtain the acoustic field amplitude in the $x$-axis and checking whether or not there was symmetry.

Case 2 - In this second case a single ceramic element $(10.0 \times 0.70 \times 0.66 \mathrm{~mm})$ was used (simple array). To measure the acoustic field amplitude of this ceramic bar a similar procedure as in case 1 was performed.

To measure the acoustic field amplitude of the ceramic bar in the $y$-axis the hydrophone was positioned at a distance of $8.5 \mathrm{~mm}$ from the ceramic element in the $x$-axis. This position was selected as the central position - point 0 (zero). The hydrophone was then moved to position $-50.0 \mathrm{~mm}$ in the $y$-axis. From this position a sweep was made in steps of $10.0 \mathrm{~mm}$ in the positive direction of the axis up to the $+50.0 \mathrm{~mm}$ position (Figure 6b). This sweep was made to obtain the acoustic field amplitude in the $y$-axis and checking whether or not there was symmetry.

Another complementary experiment was the measurement of the acoustic field amplitude of the ceramic bar based on its angular position (Figure 6c). In this measurement the hydrophone was kept fixed while the ceramic bar was rotated in order to obtain the acoustic field amplitude of this ceramic bar at different angular positions (angular radiation). In this case the hydrophone was positioned at the cross-sectional plane at a distance of $8.5 \mathrm{~mm}$ from the ceramic bar. The measurements started in the frontal face $\left(0^{\circ}\right.$ value $)$ increasing in $10^{\circ}$ steps, up to reach $360^{\circ}$ (Figure 6c).

\section{Results and Discussion}

Based on the experiments, the following results were obtained. Figure 7 shows the behavior of electrical and mechanical crosstalk as a function of the elements of the array. Electrical crosstalk is observed, its position is fixed but its attenuation increases as it travels away from the excited element (the eighth element). 


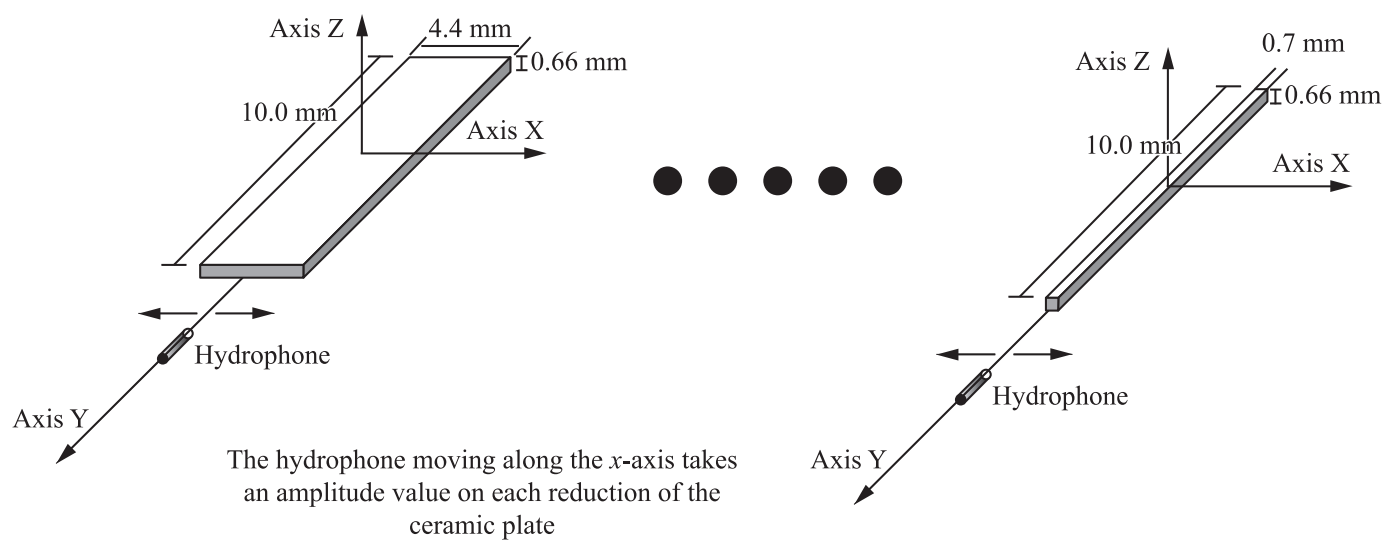

(a)

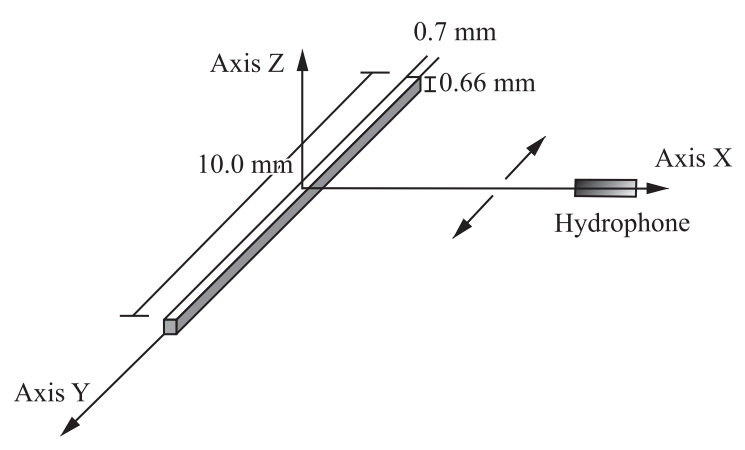

(b)

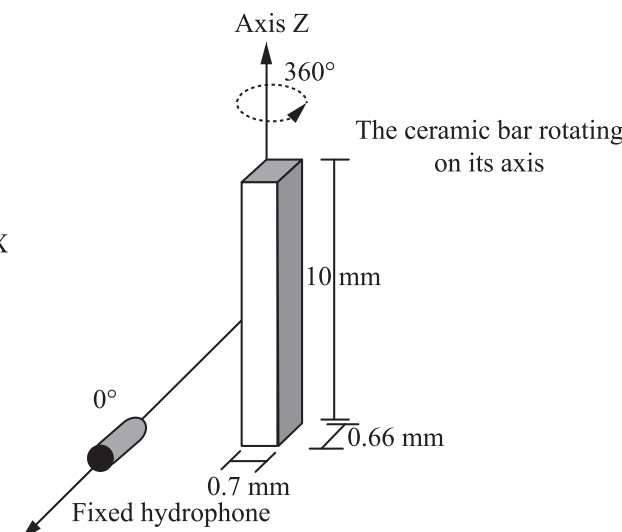

Axis $X$

(c)

Figure 6. a) Diagram of the setup to measure the acoustic field amplitude in the $x$-axis of a plate, case 1. b) Diagram of the setup to measure the acoustic field amplitude in the $x$-axis of a bar. c) Diagram of the setup to measure the acoustic field amplitude in the $x$-axis of an element of almost square section (bar), and also based on its angular position, case 2.

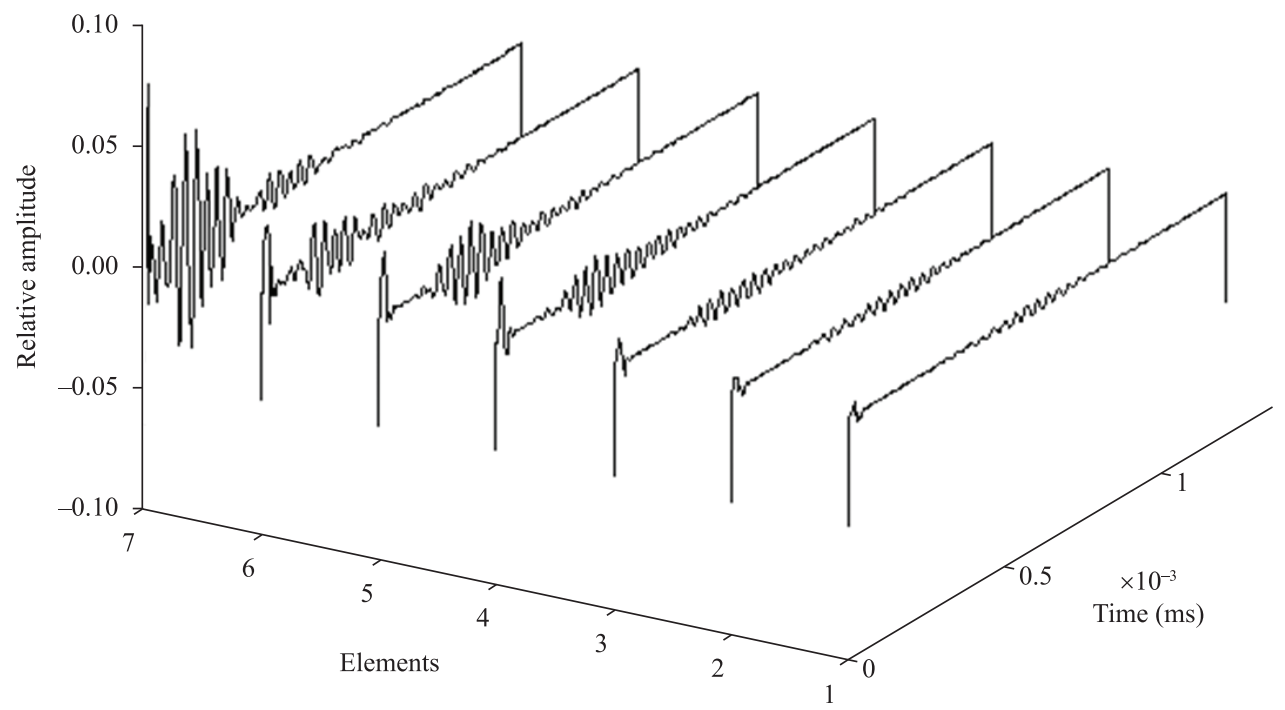

Figure 7. Response of the remaining seven elements when an eighth element is excited (position number 8 is not displayed in the figure). The values are normalized to the maximum value of the excited element ( $8^{\text {th }}$ element). 
It is possible to observe that the mechanical crosstalk, unlike the electrical crosstalk, is more intense in the closest element to the excited element and it is attenuated and delayed as it moves away from the excited element (Figure 7). This behavior is due to the propagation of the mechanical wave.

From the experimental results it is possible to obtain the attenuation values (in $\mathrm{dB}$ ) of the signals captured in the subsequent elements when the first element was excited. To calculate the attenuation value the following equation was used:

$$
d B=20 \log \frac{V_{v n}}{V_{v i}}
$$

where $V_{\mathrm{vn}}$ is the $n^{\text {th }}$ measured value and $V_{\mathrm{vi}}$ is the $i^{\text {th }}$ value (the first measured value, i.e. the value of the closest element to the excited element). The calculated attenuation is plotted in Figure 8.

In Figure 8 , it is possible to observe a negative influence (the lowest measured value is $-50 \mathrm{~dB}$ ). Normally, medical equipments work in a dynamic

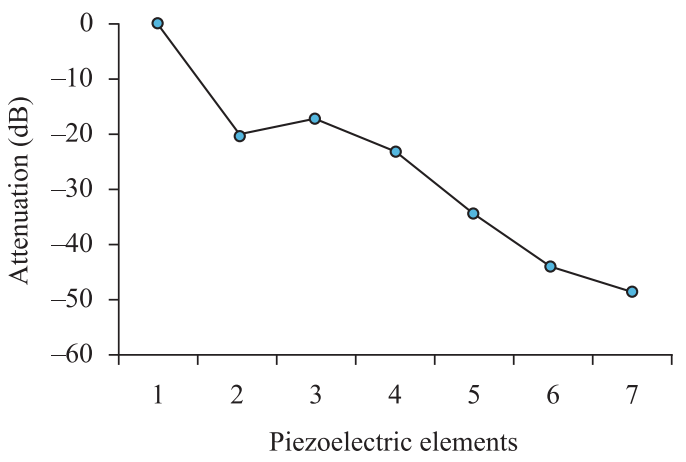

Figure 8. Attenuation obtained under the condition when one of the eight elements is excited and the response of the seven remaining elements is measured, while they are shifted away from the excited element. range around $80 \mathrm{~dB}$. The presence of crosstalk produces spurious echoes in the image obtained from a B-scan. In order to avoid this kind of spurious echoes, it is necessary to look for insulating materials with a higher degree of insulation than those of the dynamic range of equipment.

Another result is the measurement of the phase impedance when the thickness of the element decreases. In Figure 9, the displacement of the resonance frequency as a function of the thickness, as well as the effect of crosstalk is observed, with a higher influence in the elements with similar dimensions (measurements 8-12). This is due to the vibration mode of the elements, and we estimate that this fact leads to an increased crosstalk once the lateral vibration is directed to the adjacent elements through the inserted material between the elements (Gori et al., 2001; Turnbull and Foster, 1992).

Figure 9 shows the phase impedance plot, with the lateral dimensions of the sample. The arrows mark the positions of the lateral mode (ML) and the thickness mode (ME), which are clearly separated, but when dimensions begin to be closer (lateral dimension value of $1.00 \mathrm{~mm}$ ), a convergence trend is observed in both lateral and thickness modes. This is due to the physical matching phenomenon between modes that arises as a result of the approximation of the width dimension to the thickness dimension of the element. This is a counter-productive effect since it implies, among other things, in reduction of the working frequency, resulting in poorer resolution and image quality.

To avoid the lowering of the working frequency, there are some solutions; one of them would be to look for a good acoustic insulating material. Another alternative is to use piezocomposites, and a third option is the sub-cutting of the piezoelectric element, but this option represents serious technological complications.

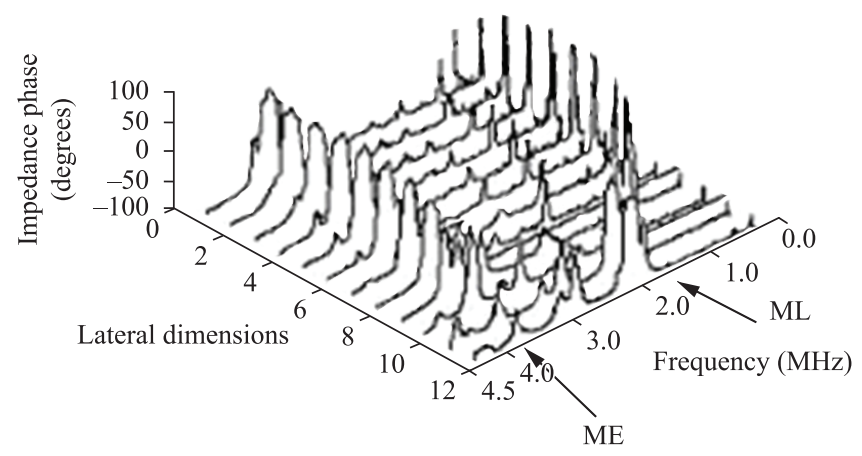

\begin{tabular}{|c|c|c|}
\hline & $\begin{array}{c}\text { Lateral dim } \\
(\mathrm{mm})\end{array}$ & $\begin{array}{c}\text { Thickness ratio } \\
\text { (thickness lateral dim.) }\end{array}$ \\
\hline 1 & 4.40 & 0.15 \\
2 & 3.80 & 0.18 \\
3 & 3.50 & 0.19 \\
4 & 3.29 & 0.20 \\
5 & 3.15 & 0.21 \\
6 & 2.80 & 0.24 \\
7 & 2.50 & 0.26 \\
8 & 2.00 & 0.33 \\
9 & 1.50 & 0.44 \\
10 & 1.00 & 0.66 \\
11 & 0.75 & 0.88 \\
12 & 0.70 & 0.94 \\
\hline
\end{tabular}

Figure 9. Measurement of the phase impedance at each reduction of the width of the element (PZ-27). The arrows mark the position of the lateral mode (ML) and the thickness mode (ME). 

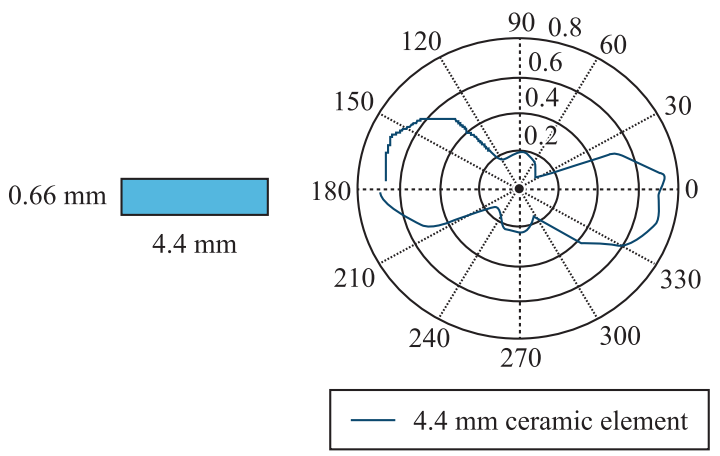

(a)

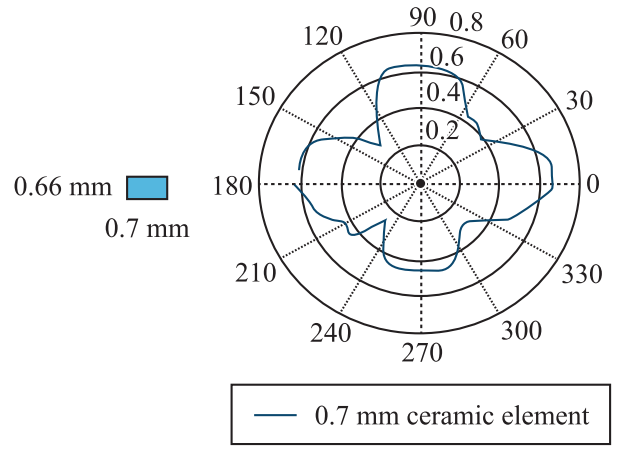

(b)

Figure 10. Radiation pattern in polar coordinates of the piezoelectric elements a) $10.0 \times 4.4 \times 0.66 \mathrm{~mm}$ and b) $10.0 \times 0.70 \times 0.66 \mathrm{~mm}$.

Figure 10a shows the radiation patterns of a $10.0 \times 4.4 \times 0.66 \mathrm{~mm}$ piezoelectric element, and Figure 10b shows the radiation pattern of a smaller piezoelectric element $(10.0 \times 0.70 \times 0.66 \mathrm{~mm})$; both radiation patterns were obtained using a goniometer. Zero degrees $\left(0^{\circ}\right)$ position corresponds to the perpendicular direction of the frontal face of each element. Figure 10 shows two cases of radiation with an aspect ratio (AR) less than 1 (a), and another near to 1 (b). In the first case (less than 1) it is observed only one small perpendicular emission to the expected one (main lobe of frontal face). These two cases will guarantee a small crosstalk, nevertheless the need of having narrow elements causes generation of hard lateral radiation as observed in the case (b) of Figure 10. This is nothing but a consequence of the modes overlapping, as it was already mentioned.

\section{Conclusion}

Crosstalk is a complex phenomenon, which represents the interaction of several mechanisms. Due to its relevance in the performance of matrix transducers, it must be studied in order to be reduced.

In conjunction, the proximity between the ceramic elements and the insulating material produces a multilayer capacitance which, ideally, should be kept as small as possible in order to reduce the crosstalk effect. Similarly, electromagnetic interactions occur.

The different vibrating modes of the ceramic elements are considerably modified by the geometry of these elements, altering the transducer performance; this alteration is more noticeable in the main radiation lobe, producing attenuation in the radiation pattern.

Based on the results obtained from the two cases presented and not having previous results from other research on the subject, it is possible to conclude that the geometry of the piezoelectric elements is of vital importance since this geometry causes crosstalk, therefore geometry and electrical connections must be considered in the design of transducers to improve their performance.

From the results we deduce that it is possible to reduce the crosstalk effect using insulating material with low electromechanical coupling coefficient between the ceramics of the array or using materials that promote good mechanical insulation between the ceramics.

This may be achieved using PZT type piezoelectric ceramics or piezocomposites. The idea is to use devices implemented with ceramic materials with sufficiently low lateral electromechanical coupling coefficient providing the mismatch of perpendicular modes.

Further work may deal with a different way of mounting the matrix transducers and with the experimentation of new insulating materials.

\section{Acknowledgements}

The authors thank the Federal University of São Carlos (UFSCar - Brazil) for its collaboration and especially to Dr. J.A. Eiras, head of the laboratory of ceramics of the UFSCar. Also, to Amauri de Jesus Xavier, for his aid and collaboration in this work, and to DGAPA-UNAM (PAPIIT-IN113610).

\section{References}

Friedrich W, Kaarmann H, Lerch R. Finite element modeling of acoustic radiation from piezoelectric phased array antennas. In: IEEE Ultrasonics Symposium: Proceedings of the IEEE Ultrasonics Symposium, 1990 Dec 4-7; Honolulu, USA. Honolulu; 1990. vol. 2, p. 763-6. http://dx.doi.org/10.1109/ULTSYM.1990.171468

Gori P, Iula A, Pappalardo M, Lamberti N, Montero de Espinosa F. Influence of the inter-element coupling on ultrasound array radiation patterns. Journal of Computational Acoustics. 2001; 9(3):773-8. http://dx.doi.org/10.1016/S0218-396X(01)00123-6 
Guess JF, Campbell JS. Acoustic properties of some biocompatible polymers at body temperature. Ultrasound in Medicine and Biology. 1995; 21(2):273-7. http://dx.doi.org/10.1016/S0301-5629(94)00117-0

Jaffe B, Cook WR, Jaffe H. Piezoelectric Ceramics. Academic Press Inc; 1971.

Kino GS, Desilets CS. Design of slotted transducer arrays with matched backings. Ultrasonic Imaging. 1979; 1(3):189-209. http://dx.doi.org/10.1016/0161-7346(79)90016-6

Sánchez Domínguez I. Methodology to evaluate the "crosstalk" in ultrasonic matrix transducers [tese]. Rio de Janeiro: Universidade Federal de Rio de Janeiro; 2003.

Sánchez Domínguez I, Von Krüger MA. Methodology to evaluate the "crosstalk" in matrix transducers. In: Congresso Brasileiro de Engenharia Biomédica: Anais do XVIII Congresso Brasileiro de Engenharia Biomédica. 2002; São José dos Campos, Brasil. São José dos Campos; 2002. p. 224-7.
Shung KK, Zipparo M. Ultrasonic transducers and arrays. IEEE Engineering in Medicine and Biology Magazine. 1996; 15(6):20-30. http://dx.doi.org/10.1109/51.544509

Smith SW, Von Ramm OT, Haran ME, Thurstone FL. Angular response of piezoelectric elements in phased array ultrasound scanners. IEEE Transactions on Sonics and Ultrasonics. 1979; SU-26(3):185-91.

Turnbull DH, Foster FS. Fabrication and characterization of transducer elements in two-dimensional arrays for medical ultrasound imaging. IEEE Transactions on Ultrasonics, Ferroelectrics and Frequency Control. 1992; 39(4):464-75. PMid:18267657. http://dx.doi.org/10.1109/58.148536

Whittingham TA. New and future developments in ultrasonic imaging. The British Journal of Radiology. 1997; 70:S11932. PMid:9534725.

Wojcik G, Desilets CS, Nikodym L, Vaughan D, Abboud N, Mould Junior, J. Computer modeling of diced matching layers. In: IEEE Ultrasonics Symposium: Proceedings of the IEEE Ultrasonics Symposium. 1996; San Antonio, USA. San Antonio; 1996. p. 1503-8.

\section{Authors \\ Israel Sánchez Domínguez, Pedro Acevedo Contla \\ Departamento de Ingeniería de Sistemas Computacionales y Automatización - IIMAS, Universidad Nacional Autónoma de México, Apdo. Postal 20-726, Admon nº 20, CP 01000, México, DF, México}

\section{Eduardo Moreno Hernández}

Instituto de Cibernética, Matemática y Física - ICIMAF, Calle 15 entre C y D, Plaza de la Revolución, CP 10400, La Habana, Cuba

\section{Marco Antônio von Krüger}

Programa de Engenharia Biomédica, COPPE, Universidade Federal do Rio de Janeiro - UFRJ, Centro de Tecnologia, Bloco G, sala 101, Cidade Universitária, Ilha do Fundão, CP 68501, CEP 21945-970, Rio de Janeiro, RJ, Brasil 